\title{
Genetic Diversity among Isolates of Phytophthora sojae in Anhui Province of China based on ISSR- PCR Markers
}

\author{
Dong Liu and Ping Li \\ College of Plant Protection, Anhui Agricultural University, 130 West of Changjiang Road, Hefei \\ 230036, Anhui, China; and Department of Horticulture and Landscape, Anqing Vocational and \\ Technical College, 99 North of Tianzhushan Road, Anqing 246003, Anhui, China
Jiulong Hu, Kunyuan Li, Zhenyu Zhao, Weiyan Wang, Jinyuan Zhang, Xu Ding, and Zhimou Gao ${ }^{1}$ College of Plant Protection, Anhui Agricultural University, 130 West of Changjiang Road, Hefei 230036, Anhui, China

\begin{abstract}
AdDitional INDEX wORDs. phytophthora root rot, soybean, molecular marker
Abstract. To explore genetic differentiation and the genetic relationships of Phytophthora sojae in Anhui Province, the inter-simple sequence repeat (ISSR) technique was used to analyze the genetic diversity of $P$. sojae. One hundred and sixty ISSR fragments were observed, including $129(80.6 \%)$ polymorphic bands. This suggested that abundant genetic diversity existed among $P$. sojae in Anhui Province. The pairwise genetic similarity coefficients among the 62 strains ranged from 0.72 to 0.96 , with a mean value of 0.85 , indicating that there was a high level of genetic variation. Phytophthora sojae strains were divided into five clusters based on neighbor-joining (NJ) analysis, and the clustering was not related to geographic source, according to Mantel's test $(r=\mathbf{0 . 3 9 3 8})$. In addition, the clustering of strains from the same geographical source had little relationship to the year of collection. Analysis of molecular variance (AMOVA) showed that $16.65 \%$ of the genetic variation was derived from the collection area and $83.35 \%$ of the genetic variation was within-population variation. The genetic flow between different geographical sources ranged from 0.623 to 2.773 , with a mean of 1.325 , suggesting that gene exchange was frequent. Genetic distance and the genetic differentiation coefficient were not related to spatial distance.
\end{abstract}

Phytophthora sojae is a destructive soilborne oomycete pathogen of soybean (Glycine max). Soybean phytophthora root and stem rot incited by $P$. sojae has been reported in Asia, Africa, Europe, North America, South America, and Oceania as soybean production is increasing around the world (Tyler, 2007). In China, phytophthora root and stem rot on soybean were reported in Fujian, Heilongjiang, and Anhui provinces (Dai et al., 2015; Lamour and Kamoun, 2009). Phytophthora sojae, a soilborne pathogen, forms a large number of oospores in the roots and stems of soybean, and these oospores can survive on residual plant material in the soil (Lamour and Kamoun, 2009). In addition, P. sojae was the primary infection that led to soybean phytophthora root rot in the next year (Garant et al., 2007). In Anhui Province, soybean phytophthora root rot might spread by soybean straw being returned to the field and inappropriate mechanized farming according to the Regulations for Control of Soybean Phytophthora Blight that was formulated by the Anhui Provincial Quality and Technical Supervision Bureau (Hefei, China). For example, uncleaned soybean combines, which carry $P$. sojae through soybean straw and soil, disperse pathogens among adjacent areas.

Some studies of the genetic diversity of $P$. sojae have been reported (Galley et al., 2007; Mohammadi et al., 2014; Silvina

Received for publication 27 Mar. 2018. Accepted for publication 2 July 2018. Funding was provided by the National Science Foundation Projects (Grant No. 31671977) and Anhui Excellent Young Talents Support Plan Key Project (Grant No. gxyqZD2018120 and Grant No. gxyqZD2016516).

${ }^{1}$ Corresponding author. E-mail: gaozhimou@126.com. et al., 2011; Wu et al., 2013, 2017). The first phylogenetic analysis of $P$. sojae was performed; its taxonomy and classification in relation to the other three Phytophthora species (Phytophthora medicaginis, Phytophthora trifolii, and Phytophthora megasperma) were evaluated by Hansen and Maxwell (1991). Researchers observed that their mitochondrial DNA content differed based on restriction fragment length polymorphism (RFLP) results (Förster et al., 1994). Meng et al. (1999) used random amplified polymorphic DNA (RAPD) markers to analyze 55 isolates of $P$. sojae from Illinois, Indiana, Iowa, and Minnesota. The results indicated that there was diversity in pathotype (race) classifications and geographic regions. Galley et al. (2007) also evaluated the genetic diversity of 32 isolates of $P$. sojae from South America and found that there was a high level of variability even among isolates in the same geographic region. Simple sequence repeats (SSRs) were identified from transcript and genomic sequences from $P$. sojae and Phytophthora ramorum (Garnica et al., 2006). Wang et al. (2007) compared P. sojae isolates from China and the United States with RAPD and ISSR to clarify the origin of $P$. sojae. The results did not support the conjecture that $P$. sojae in the United States. may be derived from China. Recently, RAPD, SSR, and ISSR were used to assess the genetic diversity of $P$. sojae isolates from China and Iran (Mohammadi et al., 2014; Wu et al., 2014, 2017). In Heilongjiang Province, China, 39 P. sojae isolates were collected from soil and soybean and genetic diversity analysis was performed by $\mathrm{Wu}$ et al. (2013) using two methods: RAPD and SSR. They found that the similarity values among $P$. sojae isolates indicated they were 
very close. The similarity values among $P$. sojae isolates ranged from $49 \%$ to $82 \%$ and $47 \%$ to $85 \%$ based on the RAPD and SSR data, respectively. RFLP, amplified fragment length polymorphism, RAPD, ISSR, and SSR were usually used for genetic diversity analysis. Among the molecular markers, ISSR is an easily used and reliable marker for investigating genetic diversity in plants, animals, and fungi (Barth et al., 2002; Budak et al., 2004). Furthermore, cluster analysis was an important focus of genetic diversity analysis. The currently popular dendrogram analysis was carried out by the unweighted pair group with arithmetic mean (UPGMA), NJ, Bayesian, and unweighted parsimony methods (Breton et al., 2008; Geuna et al., 2003; Nei and Takezaki, 1983). Among these, the UPGMA method relies on the assumption that all evolutionary lineages evolve at the same rate, but the NJ method requires no such assumption (Nei and Takezaki, 1983). This assumption cannot always be satisfied, and the UPGMA method is not an exact method in practice. However, some researchers have reported that the Bayesian method requires enormous computational time (Talavera and Castresana, 2007). Some studies showed that the $\mathrm{NJ}$ analysis gave the best reflection of the average pairwise combinations in all dendrograms (Geuna et al., 2003).

Although some previous studies have evaluated the genetic diversity of $P$. sojae, little is known about the genetic structure of $P$. sojae in Anhui Province, eastern China. Here, we investigate the genetic structure of $P$. sojae isolates from five cities (Bozhou, Fuyang, Suzhou, Bengbu, and Luan) of Anhui Province. The aim of this study was to better understand the population structure and genetic diversity of $P$. sojae in Anhui Province, through the use of ISSR markers, to further provide useful genetic information that could help to monitor the pathogen in the region and improve control strategies for $P$. sojae.

\section{Materials and Methods}

ISOlATE COLLECTION AND DNA EXTRACTION. A total of 62 single-spore $P$. sojae isolates were collected from soil and infected soybeans from five cities, Bozhou (BZ), Fuyang (FY), Suzhou (SZ), Bengbu (BB), and Luan (LA), in Anhui Province from 2008 to 2014 (Table 1). Information about the localities, collection year, cluster, and isolate number is provided in Supplemental Table 1. Phytophthora sojae from soil samples was isolated using the soybean leaf baiting method (Schmitthenner et al., 1994). Phytophthora sojae from soybean plant samples was isolated according to the method of Tyler (2007). Briefly, diseased tissues from symptomatic stems or roots were washed with sterile water and disinfected with $0.2 \%$ sodium hypochlorite. The small tissues were placed on $10 \%(\mathrm{v} / \mathrm{v}) \mathrm{V} 8$ solid medium containing $50 \mu \mathrm{g} \cdot \mathrm{mL}^{-1}$ ampicillin and $20 \mu \mathrm{g} \cdot \mathrm{mL}^{-1}$ rifampicin and cultured at $25{ }^{\circ} \mathrm{C}$ in darkness. Phytophthora sojae isolates were identified based on the morphological characteristics of the pathogen and nuclear ribosomal DNA internal transcribed spacer (ITS) analysis. The ITS region was amplified with specific primers for $P$. sojae, ITS4 and ITS6 (Dai et al., 2015). Phytophthora sojae isolates were preserved at $12{ }^{\circ} \mathrm{C}$ at the Mycology and Plant Fungal Disease Laboratory of Anhui Agricultural University (Hefei, China). The P. sojae strains used in this study were cultured on $10 \% \mathrm{~V}_{8}$ medium at $25^{\circ} \mathrm{C}$ in the dark for $5 \mathrm{~d}$. Then, six to eight plugs of actively growing mycelia were obtained with a 9-mm cork borer, and $P$. sojae discs were placed into $10 \% \mathrm{~V}_{8}$ liquid medium. Phytophthora sojae strains were cultured at $25^{\circ} \mathrm{C}$ for $3-5 \mathrm{~d}$, and mycelia were harvested for DNA isolation. Mycelia of $P$. sojae strains were ground into powder with liquid nitrogen, and the $P$. sojae genomic DNA was isolated with the CTAB method according to Tyler et al. (1995). All DNA samples were quantified using a spectrophotometer (NanoDrop ND-1000; Thermo Fisher Scientific, Waltham, MA) and then diluted to $100 \mathrm{ng} \cdot \mu \mathrm{L}^{-1}$ with double-distilled $\mathrm{H}_{2} \mathrm{O}\left(\mathrm{ddH}_{2} \mathrm{O}\right)$ for inter-simple sequence repeatpolymerase chain reaction (ISSR-PCR) amplification.

ISSR-PCR AMPLIFICATION. Fifty-four primers were synthesized by Sangon Biotechnology (Shanghai, China) and initially screened on 20 isolates. Thirteen primers (Table 2) that produced clear and reproducible bands were selected for ISSR-PCR amplification. The amplifications were performed in a $25-\mu \mathrm{L}$ reaction mixture $[12.5 \mu \mathrm{L} 2 \times$ Taq Plus PCR Master Mix (KT205-02; Tiangen Biotech Co., Beijing, China), $0.2 \mu \mathrm{M}$ primer, $9.5 \mu \mathrm{L} \mathrm{ddH}_{2} \mathrm{O}$, and $0.5 \mu \mathrm{L}$ template DNA], and the following PCR program was run using a thermal cycler (Arktik TCA0002; Thermo Fisher Scientific): initial denaturation for 3 min at $94{ }^{\circ} \mathrm{C}, 35$ cycles of denaturation at $94{ }^{\circ} \mathrm{C}$ for $30 \mathrm{~s}$, annealing at a specific temperature (given in Table 2) for $30 \mathrm{~s}$, and extension at $72{ }^{\circ} \mathrm{C}$ for $90 \mathrm{~s}$, followed by a final extension at $72{ }^{\circ} \mathrm{C}$ for $10 \mathrm{~min}$. The PCR products were separated on $1.8 \%$ agarose gels containing ethidium bromide in Tris-acetateEDTA buffer at $5 \mathrm{~V} \cdot \mathrm{cm}^{-1}$ for $3 \mathrm{~h}$. Then, the agarose gels were visualized under an ultraviolet transilluminator in an imaging system (EC3 300; Ultraviolet Products, Upland, CA). All amplifications were repeated three times.

DAta AnAlysis. The DNA bands from the ISSR-PCR amplification were recorded as present (1) or absent (0) and converted into a binary matrix. Cluster analysis of $P$. sojae was performed on the basis of a genetic distance matrix, and the dendrogram was constructed by NJ with NTSYS-pc 2.1(Rohlf, 2000). The observed number of alleles (NA), effective number of alleles (NE), Nei's genetic diversity $(h)$, Shannon's information index $\left(I_{\mathrm{s}}\right)$, total genetic diversity $\left(H_{\mathrm{t}}\right)$, and genetic diversity within groups $\left(H_{\mathrm{s}}\right)$ of $P$. sojae were computed with POPGENE 1.3.1 software (Yeh et al., 1999). The genetic differentiation coefficient $\left(G_{\mathrm{ST}}\right)$, gene flow coefficient $\left(N_{\mathrm{m}}\right)$, genetic identity (I), and genetic distance (D) among geographical groups of $P$. sojae were also calculated with POPGENE

Table 1. Information of 62 isolates Phytophthora sojae in five cities in Anhui Province, China.

\begin{tabular}{ll}
\hline Sampling site (city) & Isolate no. \\
\hline Bozhou & BZ1, BZ2, BZ3, BZ4, BZ5, BZ6, BZ7, BZ8, BZ9, BZ10, BZ11, BZ12, BZ13, BZ14, BZ15, BZ16, BZ17, BZ18, \\
& BZ19, BZ20, BZ21 \\
Fuyang & FY1, FY2, FY3, FY4, FY5, FY6, FY7, FY8, FY9, FY10, FY11 \\
Suzhou & SZ1, SZ2, SZ3, SZ4, SZ5 \\
Bengbu & BB1, BB2, BB3, BB4, BB5, BB6, BB7, BB8, BB9, BB10, BB11, BB12, BB13, BB14, BB15, BB16, BB17, BB18 \\
Luan & LA1, LA2, LA3, LA4, LA5, LA6, LA7 \\
\hline
\end{tabular}


Table 2. Properties of ISSR primers used for amplification of Phytophthora sojae isolates in this study.

\begin{tabular}{|c|c|c|c|c|c|c|c|}
\hline Primer & Sequence $5^{\prime}-3^{\prime}$ & Annealing temp $\left({ }^{\circ} \mathrm{C}\right)$ & Bands amplified (no.) & Polymorphic bands (no.) & Polymorphism (\%) & $h^{\mathrm{z}}$ & $I_{\mathrm{s}}$ \\
\hline ILE35 & $(\mathrm{AC})_{8} \mathrm{~T}$ & 55 & 13 & 11 & 84.6 & 0.2128 & 0.3388 \\
\hline ILE46 & $(\mathrm{GA})_{8} \mathrm{CT}$ & 54 & 12 & 10 & 83.3 & 0.3020 & 0.4523 \\
\hline ILE67 & $(\mathrm{GA})_{8} \mathrm{CC}$ & 56 & 13 & 11 & 84.6 & 0.2870 & 0.4324 \\
\hline ILE112 & $(\mathrm{AAG})_{6} \mathrm{C}$ & 55 & 12 & 10 & 83.3 & 0.2097 & 0.3420 \\
\hline ILE120 & $\mathrm{CAC}(\mathrm{GA})_{7}$ & 54 & 10 & 9 & 90.0 & 0.2116 & 0.3382 \\
\hline ILE131 & $\mathrm{CAC}(\mathrm{CA})_{7}$ & 53 & 11 & 9 & 81.8 & 0.3055 & 0.4445 \\
\hline UBC811 & $(\mathrm{GA})_{8} \mathrm{C}$ & 50 & 11 & 7 & 63.6 & 0.1889 & 0.2850 \\
\hline UBC 835 & $(\mathrm{AG})_{8} \mathrm{YC}$ & 50 & 15 & 11 & 73.3 & 0.2257 & 0.3409 \\
\hline UBC 841 & $(\mathrm{GA})_{8} \mathrm{YC}$ & 54 & 13 & 10 & 76.9 & 0.2692 & 0.4068 \\
\hline UBC866 & $(\mathrm{CTC})_{6}$ & 60 & 11 & 9 & 81.8 & 0.2648 & 0.4024 \\
\hline UBC873 & $(\mathrm{GACA})_{4}$ & 54 & 13 & 12 & 92.3 & 0.3352 & 0.4973 \\
\hline
\end{tabular}

${ }^{\mathrm{z}} h=$ Nei's gene diversity; $I_{\mathrm{s}}=$ Shannon's information index as a measure of gene diversity.

software for all pairwise combinations of populations (Nei, 1972; Slatkin and Barton, 1989; Yeh et al., 1999). The Mantel test was used to analyze the significance of the correlation between genetic distance and geographical distance among different geographic groups (Miller, 1997). Analysis of molecular variance within and between $P$. sojae populations was evaluated according to Excoffier et al. (1992).

\section{Results}

PRIMER SCREENING AND POLYMORPHISM OF ISSR-PCR PRODUCTS. In the preliminary test, 54 primers were screened against 20 isolates, and 13 primers that produced clear and reproducible bands were selected for ISSR-PCR amplification to detect genetic characteristics of $P$. sojae strains in Anhui Province (Table 2). The annealing temperatures of 13 primers ranged from 50 to $60{ }^{\circ} \mathrm{C}$ (Table 2). An example of the DNA banding profiles of primer ILE79 is shown in Supplemental Fig. 1. The minimum and maximum number of bands generated by any primer were 10 (ILE120) and 15 (UBC835), respectively. The average number of bands was 12.2. The percentage of polymorphism ranged from $63.6 \%$ (UBC811) to $92.3 \%$ (UBC873).

As shown in Table 2, the $h$ values ranged from 0.1889 to 0.3352. $I_{\mathrm{s}}$ ranged from 0.2850 to 0.4973 . The values of $h$ and $I_{\mathrm{s}}$ indicated that these 13 primers were appropriate for distinguishing diverse isolates of $P$. sojae. The genetic diversity of different populations was compared and is shown in Table 3. A total of 13 primers produced 160 bands, of which 129 were polymorphic, accounting for a polymorphism of $80.6 \%$. In Bozhou City, ISSR primers generated 145 bands, which included 84 polymorphic bands, and the percentage of polymorphism was $\approx 57.9 \%$. The percentages of polymorphism in the Fuyang, Suzhou, Bengbu, and Luan areas were 51.8\%, $34.8 \%, 65.8 \%$, and $51.1 \%$, respectively (Table 3 ). These results suggested that polymorphism was abundant among different $P$. sojae isolates in Anhui Province. According to POPGENE analysis results, the $H_{\mathrm{t}}$ of the 62 isolates was 0.2211 , and the $H_{\mathrm{s}}$ was 0.1647 . The results of AMOVA indicated that $16.65 \%$ of the total variation was attributable to population divergence between the populations and $83.35 \%$ was attributable to individual differences within populations $(P<0.001)$. There were significant genetic differences within populations.
Table 3. Genetic variations and polymorphic features among isolates of Phytophthora sojae.

\begin{tabular}{lccccccc}
\hline & TB & & & \multicolumn{5}{c}{ NE } \\
Population $^{z}$ & (no.) $^{\mathrm{y}}$ & PB (no.) & PPB (\%) & NA (no.) & (no.) & $h$ & $I_{\mathrm{s}}$ \\
\hline BZ & 145 & 84 & 57.9 & 1.58 & 1.34 & 0.20 & 0.30 \\
FY & 143 & 74 & 51.8 & 1.52 & 1.31 & 0.18 & 0.27 \\
SZ & 138 & 48 & 34.8 & 1.35 & 1.24 & 0.13 & 0.19 \\
BB & 149 & 98 & 65.8 & 1.66 & 1.39 & 0.23 & 0.34 \\
LA & 139 & 71 & 51.1 & 1.51 & 1.32 & 0.18 & 0.27 \\
Summary & 160 & 129 & 80.6 & 1.81 & 1.41 & 0.25 & 0.38 \\
\hline
\end{tabular}

${ }_{\mathrm{z}} \mathrm{BZ}=$ Bozhou; FY = Fuyang; $\mathrm{SZ}=$ Suzhou; $\mathrm{BB}=$ Bengbu; LA = Luan. ${ }^{\mathrm{y}} \mathrm{TB}=$ total bands; $\mathrm{PB}=$ number of polymorphic bands; $\mathrm{PPB}=$ percentage of polymorphic bands; NA = number of alleles (counts the number of alleles with nonzero frequency); $\mathrm{NE}=$ effective number of alleles (estimates the reciprocal of homozygosity); $h=$ Nei's gene diversity; $I_{\mathrm{s}}=$ Shannon's information index as a measure of gene diversity.

ISSR CLUSTER ANALYSIS. Neighbor-joining dendrograms were constructed based on genetic distances. The results indicated that 62 isolates of $P$. sojae could be divided into five groups (Fig. 1). Clusters i, ii, iii, and iv included 5, 2, 6, and 13 isolates of $P$. sojae, respectively. The other 36 isolates of $P$. sojae formed group v. In Fig. 1, Pop BZ was distributed into five clusters (i, ii, iii, iv, and v), and Pop FY was also distributed into two clusters (iv and v). All the isolates of Pop SZ and Pop LA were in group $\mathrm{v}$, whereas Pop BB was distributed into clusters iii and $v$. The reason that the isolates from different locations were distributed across the dendrogram may have been the exchange of the pathogen among locations (Lamour and Kamoun, 2009). Some agricultural practices in northern Anhui Province, such as using soybean stalks for livestock feed and organic fertilizer without proper treatment, probably resulted in exchanging of the pathogen between farms (Wen, 2003). In these areas, soybean stalks were often used for livestock feed and organic fertilizer, and they were traded and transported in these cities. Soybean phytophthora root rot also might be spread by inappropriate mechanized farming. For example, renting an untreated crop harvester, which would carry $P$. sojae through soybean straw and soil, can disperse the pathogen among adjacent areas. Most of the isolates from the same region grouped together, but isolates from the same location showed no clustering based on the year of sampling. 


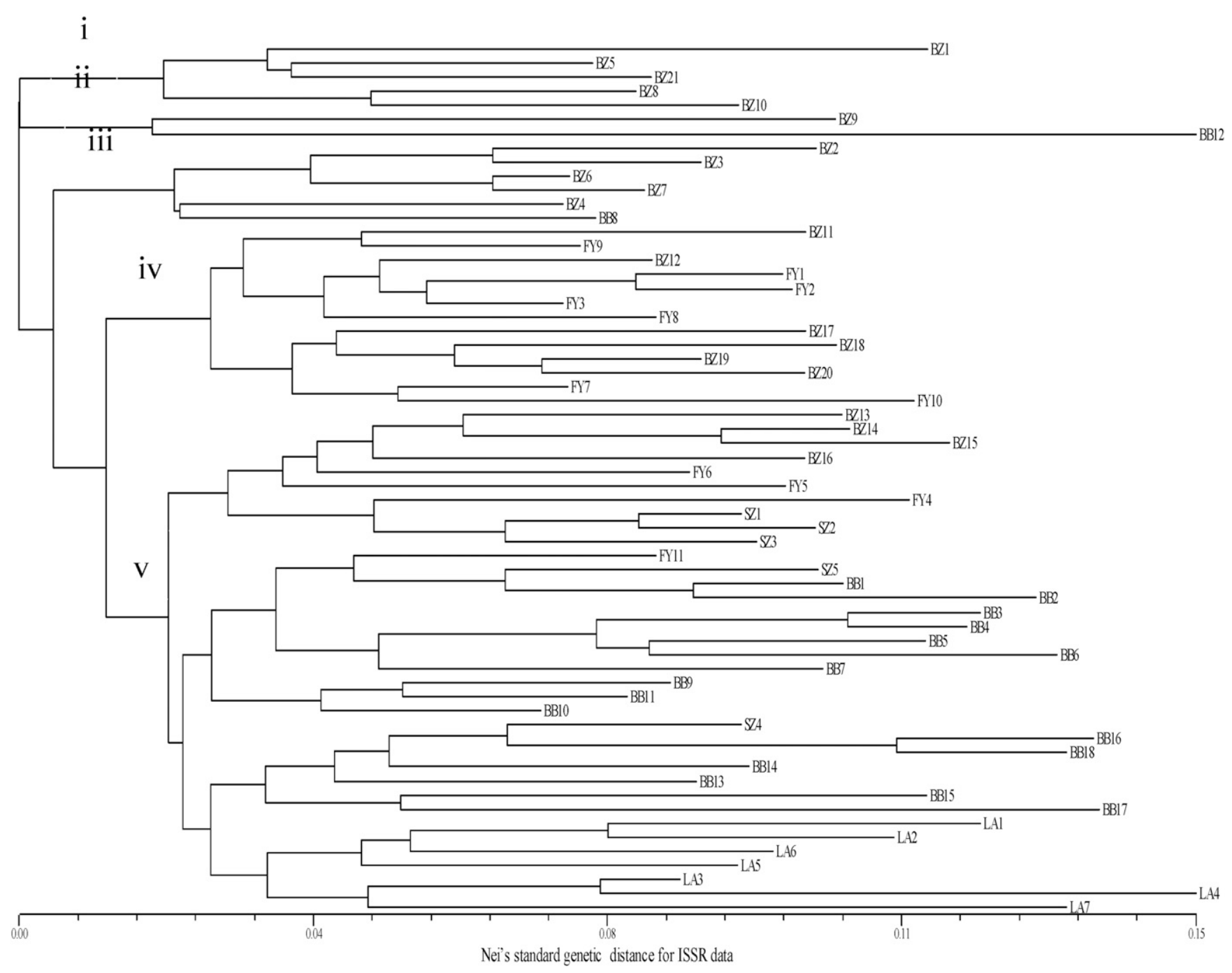

Fig. 1. Neighbor-joining dendrogram of 62 isolates of Phytophthora sojae based on genetic distances; i, ii, iii, iv, and v represent five distinct clusters.

GENE FLOW AND GENETIC DIFFERENTIATION OF THE FIVE LOCATIONS. The values of $G_{\text {st }}$ and $N_{\mathrm{m}}$ among the five locations were calculated with POPGENE version 1.3.1 and are shown in Table 4 . The average $G_{\text {st }}$ was 0.2550 , which suggested that the genetic differentiation among the five locations was $25.5 \%$. The coefficient of genetic differentiation was $74.5 \%$ in each location and higher than the coefficient of genetic differentiation among the five locations. The low level of $G_{\text {st }}$ was caused by a high $N_{\mathrm{m}}$, according to Wright (1978). $N_{\mathrm{m}}$ was calculated with the following equation: $N_{\mathrm{m}}=0.25\left(1-G_{\mathrm{st}}\right) / G_{\mathrm{st}}$. The values of $N_{\mathrm{m}}$ ranged from 0.623 to 2.773 , with an average of 1.325 , which was higher than the threshold value of 1 (Wright, 1978). These results indicated that gene exchange between different locations was abundant, and $N_{\mathrm{m}}$ among the five locations led to differences in $G_{\text {st }}$. For instance, the minimum $N_{\mathrm{m}}(0.623)$ was between Pop SZ and Pop LA; however, the maximum $G_{\text {st }}$ was 0.286 . By contrast, the maximum $N_{\mathrm{m}}(2.773)$ was between Pop FY and Pop BZ, whereas the $G_{\text {st }}(0.083)$ value between these two sites was the lowest. The correlation of population genetic distance and geographic distance was tested using Mantel's test. The results indicated that the correlation between spatial and genetic distance was low $(r=0.3938, P=0.152)$.
Genetic IDENTITy And genetic distances among POPUlations of $\boldsymbol{P}$. SOJAE. Matrices of genetic distances and genetic identities (Nei''s original measures) among the five locations were established. Genetic identity (I) and genetic distance (D) values were obtained from pairwise comparisons (Table 5), and the results indicated that the highest genetic identity was 0.9701 , between Pop BZ and Pop FY, whereas their genetic distance $(0.0304)$ was the smallest. The lowest genetic identity was 0.8871 , between Pop SZ and Pop LA, whereas their genetic distance (0.1197) was the largest. These results agreed with the ISSR cluster analysis and could be explained by the $N_{\mathrm{m}}$.

\section{Discussion}

It is necessary to study the genetic structure of plant pathogenic fungi and oomycetes for effective control of disease (Wolfe and Caten, 1987). A large number of studies have shown that molecular markers can detect pathogen population genetic variation among strains to a certain extent, including that derived from pathogenic mutations, strains from different geographic origins and hosts, etc. (Goodwin, and Annis, 1991; 
Table 4. Gene flow $\left[N_{\mathrm{m}}\right.$ (above diagonal) $]$ and genetic differentiation coefficient $\left[G_{\mathrm{st}}\right.$ (below diagonal)] among Phytophthora sojae populations.

\begin{tabular}{lccccc}
\hline Location & Bozhou & Fuyang & Suzhou & Bengbu & Luan \\
\hline Bozhou & - & 2.773 & 0.853 & 1.766 & 1.121 \\
Fuyang & 0.083 & - & 1.025 & 1.458 & 1.144 \\
Suzhou & 0.227 & 0.196 & - & 0.910 & 0.623 \\
Bengbu & 0.124 & 0.146 & 0.216 & - & 1.574 \\
Luan & 0.182 & 0.179 & 0.286 & 0.137 & - \\
\hline
\end{tabular}

Table 5. Genetic identity [I (above diagonal)] and genetic distances [D (below diagonal)] among Phytophthora sojae populations.

\begin{tabular}{lccccc}
\hline Location & Bozhou & Fuyang & Suzhou & Bengbu & Luan \\
\hline Bozhou & - & 0.9701 & 0.9083 & 0.9372 & 0.9186 \\
Fuyang & 0.0304 & - & 0.9338 & 0.9300 & 0.9286 \\
Suzhou & 0.0962 & 0.0685 & - & 0.9045 & 0.8871 \\
Bengbu & 0.0649 & 0.0726 & 0.1004 & - & 0.9390 \\
Luan & 0.0849 & 0.0741 & 0.1197 & 0.0629 & - \\
\hline
\end{tabular}

Manulis et al., 1993; Nyasse et al., 1999). In this study, ISSR marker technology was used to analyze the genetic diversity of $P$. sojae in Anhui Province, and clear and reproducible ISSRPCR amplification bands were observed. The high percentage of polymorphic loci showed that 62 isolates of $P$. sojae had abundant genetic diversity, and the polymorphism rate was $80.6 \%$. The percentages of polymorphic bands in Heilongjiang Province, Fujian Province, Argentina, and the United States were $71 \%, 60 \%, 71 \%$, and $84 \%$ according to previous reports (Galley et al., 2007; Wu et al., 2013, 2017). Isolates from Anhui Province had higher genotypic diversity than those from Heilongjiang Province, Fujian Province, and Argentina, but this diversity was lower than that of those from the United States. There was no significant difference in genetic diversity between populations, and the difference was mainly due to genetic variation within the population. The same phenomenon was also observed in previous reports (Wang et al., 2007, 2017).

ISSR clustering results showed that the strains from the same group did not all belong to the same genotype, and the division of the clustering group was not directly correlated with geographic origin (Galley et al., 2007; Wang et al., 2007). There was genetic differentiation between strains, and the possible reasons for this were gene mutation, genetic drift, gene flow, reproduction and mating system, and selection pressure from primary resistant soybean cultivars (Lamour and Kamoun, 2009; McDonald and Linde, 2002). Mutations were the root source of genetic differentiation and could directly change the gene sequences of individuals and generate a new allele within a population. Genetic drift affected the probability of mutation, which might result in an increase in genetic diversity (Silvina et al., 2011). Some studies have shown that gene flow plays an important role in genetic differentiation and species diversity and has a positive effect on the formation and adaptive evolution of species (Garant et al., 2007; Seehausen, 2004). Gene flow describes the movement of alleles and genotypes of toxic mutants between populations from different regions, and it is associated with genetic differentiation. In addition, the evolution of asexual reproduction and heterozygous hybridization of $P$. sojae (Drenth et al., 1996) probably led to genetic differentiation. The selection pressure from soybean cultivars with primary resistance might drive an increase in the mutation frequency of pathogenic alleles (Meng et al., 1999). Lohnes et al. (1996) and Kyle et al. (1998) evaluated the soybean phytophthora root rot resistance of soybean germplasm resources from central and southern China, which contains multiple physiological races of $P$. sojae. The results showed that the identified resources were generally resistant to soybean phytophthora root rot, especially those from the provinces of Anhui, Jiangsu, Zhejiang, Shandong, and Henan. Therefore, potential selection pressure on $P$. sojae existed in these areas.

Abundant genetic diversity existed among $P$. sojae in Anhui Province. The average $N_{\mathrm{m}}$ was 1.325 , which was greater than the threshold value of 1 (Wright, 1978), indicating that gene exchange between different locations was abundant. Inappropriate agricultural practices in Anhui Province might disperse the pathogen. Therefore, for the prevention and control of this disease, it is necessary to strengthen the plant quarantine to cut off the long-distance transmission channels (Parke et al., 2014). We should fully tap the basic ability of the resistant cultivars controlled by minor genes, and at the same time, we should use fungicides more scientifically and in rotation to avoid resistance due to genetic variation (Dorrance, 2018). Research on the genetic diversity of $P$. sojae in Anhui would supply useful information to improve the control strategies for $P$. sojae (Parke et al., 2014). Moreover, because $P$. sojae poses a great risk to soybean cultivation in Anhui Province, Anhui Agricultural University, the Anhui Institute of Standardization (Hefei, China), the Plant Protection Research Institute of Anhui Academy of Agricultural Sciences (Hefei, China), the Plant Protection Station of Anhui Province (Hefei, China) and the Feidong Agricultural Technology Promotion Center of Anhui Province (Hefei, China) jointly drafted two monitoring regulations, rules for investigation and forecasting technology for soybean phytophthora blight $(P$. sojae) and regulations for the control of soybean phytophthora blight (Province of Anhui, $2013 a, b)$. The former regulation stipulated the recording of items and grading indicators of the incidence of soybean phytophthora blight in Anhui Province, the systematic investigation of disease conditions, and the relevant methods for field surveys and forecasting, and it also provides guidance for effective monitoring and investigation of soybean phytophthora blight in Anhui Province. The latter regulation emphasized that prevention and control must be combined to prevent and treat soybean phytophthora blight. First, inspections were conducted and soybeans were quarantined in accordance with laws and regulations to prevent the intrusion and spread of pests. Second, to suppress and eliminate $P$. sojae, it is important to make rational use of disease-resistant cultivars in combination with disease-causing types (Dorrance, 2018). In accordance with the needs of cultivation and management, the use of such cultivars should be combined with agricultural operations to create farmland ecological environments that are conducive to crop growth, and development that is not conducive to the occurrence of diseases should be practiced. Finally, chemical control and biological control should be combined (Dorrance, 2018; Schmitthenner, 1985).

\section{Literature Cited}

Barth, S., A.E. Melchinger, and T.H. Lübberstedt. 2002. Genetic diversity in Arabidopsis thaliana L. Heynh. investigated by cleaved amplified polymorphic sequence (CAPS) and inter-simple sequence repeat (ISSR) markers. Mol. Ecol. 11:495-505. 
Breton, C., C. Pinatel, F. Medail, F. Bonhomme, and A. Berville. 2008 Comparison between classical and Bayesian methods to investigate the history of olive cultivars using SSR-polymorphisms. Plant Sci. 175:524-532.

Budak, H., R.C. Shearman, I. Parmaksiz, and I. Dweikat. 2004. Comparative analysis of seeded and vegetative biotype buffalograsses based on phylogenetic relationship using ISSRs, SSRs, RAPDs, and SRAPs. Theor. Appl. Genet. 109:280-288.

Dai, Y.L., T.F. Liu, L.F. Zhang, Z.H. Li, W.W. Guo, S. Cao, Y.M. Pan, F.X. Chen, and Z.M. Gao. 2015. First report of phytophthora root and stem rot caused by Phytophthora sojae on soybean in Taihe, China. Plant Dis. 99:1861-1862.

Dorrance, A.E. 2018. Management of Phytophthora sojae of soybean: A review and future perspectives. Can. J. Plant Pathol. 40:210-219.

Drenth, A., S.C. Whisson, D.J. MacLean, J.A.G. Irwin, N.R. Obst, and M.J. Ryley. 1996. The evolution of races of Phytophthora sojae in Australia. Phytopathology 86:163-169.

Excoffier, L., P.E. Smouse, and J.M. Quattro. 1992. Analysis of molecular variance inferred from metric distances among DNA haplotypes: Application to human mitochondrial DNA restriction data. Genetics 131:479-491.

Förster, H., B.M. Tyler, and M.D. Coffey. 1994. Phytophthora sojae races have arisen by clonal evolution and by rare outcrosses. Mol. Plant Microbe Interact. 7:780-791.

Galley, M., A.M. Ramos, D. Dokmetzian, and S.E. Lopez. 2007. Genetic variability of Phytophthora sojae isolates from Argentina. Mycologia 99:877-883.

Garant, D., S.E. Forde, and A.P. Hendry. 2007. The multifarious effects of dispersal and gene flow on contemporary adaptation. Funct. Ecol. 21:434-443.

Garnica, D.P., A.M. Pinzón, L.M. Quesada-Ocampo, A.J. Bernal, E. Barreto, N.J. Grünwald, and S. Restrepo. 2006. Survey and analysis of microsatellites from transcript sequences in Phytophthora species: Frequency, distribution, and potential as markers for the genus. BMC Genomics 7:1-11.

Geuna, F., M. Toschi, and D. Bassi. 2003. The use of AFLP markers for cultivar identification in apricot. Plant Breeding 122:526-531.

Goodwin, P.H. and S.L. Annis. 1991. Rapid identification of genetic variation and pathotype of Leptosphaeria maculans by random amplified polymorphic DNA assay. Appl. Environ. Microbiol. 57:2482-2485.

Hansen, E.M. and D.P. Maxwell. 1991. Species of the Phytophthora megasperma complex. Mycologia 83:376-381.

Kyle, D.E., C.D. Nickell, R.L. Nelson, and W.L. Pedersen. 1998. Response of soybean accessions from provinces in southern China to Phytophthora sojae. Plant Dis. 82:555-559.

Lamour, K. and S. Kamoun. 2009. Oomycete genetics and genomics: Diversity, interactions and research tools. Wiley, Hoboken, NJ.

Lohnes, D.G., C.D. Nickell, and A.F. Schmitthenner. 1996. Origin of soybean alleles for Phytophthora resistance in China. Crop Sci. 36:1689-1692.

Manulis, S., N. Kogan, and M. Reuven. 1993. Use of the RAPD technique for identification of Fusarium oxysporum f. sp. dianthi from carnation. Phytopathology 84:98-101.

McDonald, B.A. and C. Linde. 2002. Pathogen population genetics, evolutionary potential, and durable resistance. Annu. Rev. Phytopathol. 40:349-379.

Meng, X.Q., R.C. Shoemaker, and X.B. Yang. 1999. Analysis of pathogenicity and genetic variation among Phytophthora sojae isolates using RAPD. Mycol. Res. 103:173-178.

Miller, M.P. 1997. TFPGA: Tools for population genetic analyses. Version 1.3. 21 Jan. 2013. <http://www.marksgenetcsoftware.net/tfpga.htm>.

Mohammadi, A., A. Alizadeh, J. Mozafari, M. Mirabolfathi, and N.N. Mofrad. 2014. Genetic diversity of phytophthora sojae in Iran. Pak. J. Biol. Sci. 11:302-305.
Nei, M. 1972. Genetic distance between populations. Amer. Nat. 106:283-292.

Nei, M. and N. Takezaki. 1983. Estimation of genetic distances and phylogenetic trees from DNA analysis. Proc. 5th World Congr. Genet. Appl. Livestock Production 21:405-412.

Nyasse, S., L. Grivet, and A.M. Risterucci. 1999. Diversity of Phytophthora megakarya in Central and West Africa revealed by isozyme and RAPD makers. Mycol. Res. 103:1225-1234.

Parke, J.L., B.J. Knaus, V.J. Fieland, C. Lewis, and N.J. Grünwald. 2014. Phytophthora community structure analyses in Oregon nurseries inform systems approaches to disease management. Phytopathology 104:1052-1062.

Province of Anhui. 2013a. Anhui Code of Regulations, regulations for control of soybean phytophthora blight. 29 July 2013. <http://bzxx. ahbz.org.cn/standard_detail.html?flaglogin=0\&id=3561079>.

Province of Anhui. 2013b. Anhui Code of Regulations, rules for investigation and forecast technology of soybean phytophthora blight (Phytophthora sojae Kaufmann \& Gerdemann). 29 July 2013. <http:// bzxx.ahbz.org.cn/standard_detail.html?flaglogin $=0 \& \mathrm{id}=3561078>$.

Rohlf, F.J. 2000. NTSYSpc: Numerical taxonomy and multivariate analysis system. Version 2.1. Exeter Software, Setauket, NY.

Schmitthenner, A.F. 1985. Problems and progress in control of phytophthora root rot of soybean. Plant Dis. 69:362-368.

Schmitthenner, A.F., M. Hobe, and R. Bhat. 1994. Phytophthora sojae races in Ohio over a 10-year interval. Plant Dis. 78:269-276.

Seehausen, O. 2004. Hybridization and adaptive radiation. Trends Ecol. Evol. 19:198-207.

Silvina, S., W. Damitha, A.E. Dorrance, and A.E. Robertson. 2011. Comparison of three microsatellite analysis methods for detecting genetic diversity in Phytophthora sojae (Stramenopila: Oomycete). Biotechnol. Lett. 33:2217-2223.

Slatkin, M. and N.H. Barton. 1989. A comparison of three indirect methods for estimating the average level of gene flow. Evolution 43:1349-1368.

Talavera, G. and J. Castresana. 2007. Improvement of phylogenies after removing divergent and ambiguously aligned blocks from protein sequence alignments. Syst. Biol. 56:564-577.

Tyler, B.M. 2007. Phytophthora sojae: Root rot pathogen of soybean and model oomycete. Mol. Plant Pathol. 8:1-8.

Tyler, B.M., H. Förster, and M.D. Coffey. 1995. Inheritance of avirulence factors and restriction fragment length polymorphism markers in outcrosses of oomycete Phytophthora sojae. Mol. Plant Microbe Interact. 8:515-523.

Wang, Z., Y. Wang, Z. Zhang, and X. Zheng. 2007. Genetic relationships among Chinese and American isolates of Phytophthora sojae by ISSR markers. Biodiversity Sci. 15:215-223.

Wen, J.Z. 2003. Detection and identification of Phytophthora sojae and transmission of phytophthora root rot of soybean. Acta Phytopathol. Sin. 33:191-192.

Wolfe, M.S. and C.E. Caten. 1987. Populations of plant pathogens: Their dynamics and genetics. Blackwell, Hoboken, NJ.

Wright, S. 1978. Evolution and the genetics of populations. Univ. Chicago Press, Chicago, IL.

Wu, J.J., P.F. Xu, L.J. Liu, J.S. Wang, W.G. Lin, S.Z. Zhang, and L. Wei. 2013. Genetic diversity of Phytophthora sojae isolates in Heilongjiang province in China assessed by RAPD and EST-SSR. Proc. SPIE 8762:1-4.

Wu, M., B. Li, P. Liu, Q. Weng, J. Zhan, and Q. Chen. 2017. Population genetic analyses of Phytophthora sojae in Fujian, China. Plant Pathol. 66:1182-1190.

Yeh, F.C., R.C. Yang, and T. Boyle. 1999. POPGENE version 1.32. 1 Dec. 2016. <https://sites.ualberta.ca/ fyeh/popgene_download. html>. 
Supplemental Table 1. Information for isolates Phytophthora sojae from Anhui Province, China, used in this study.

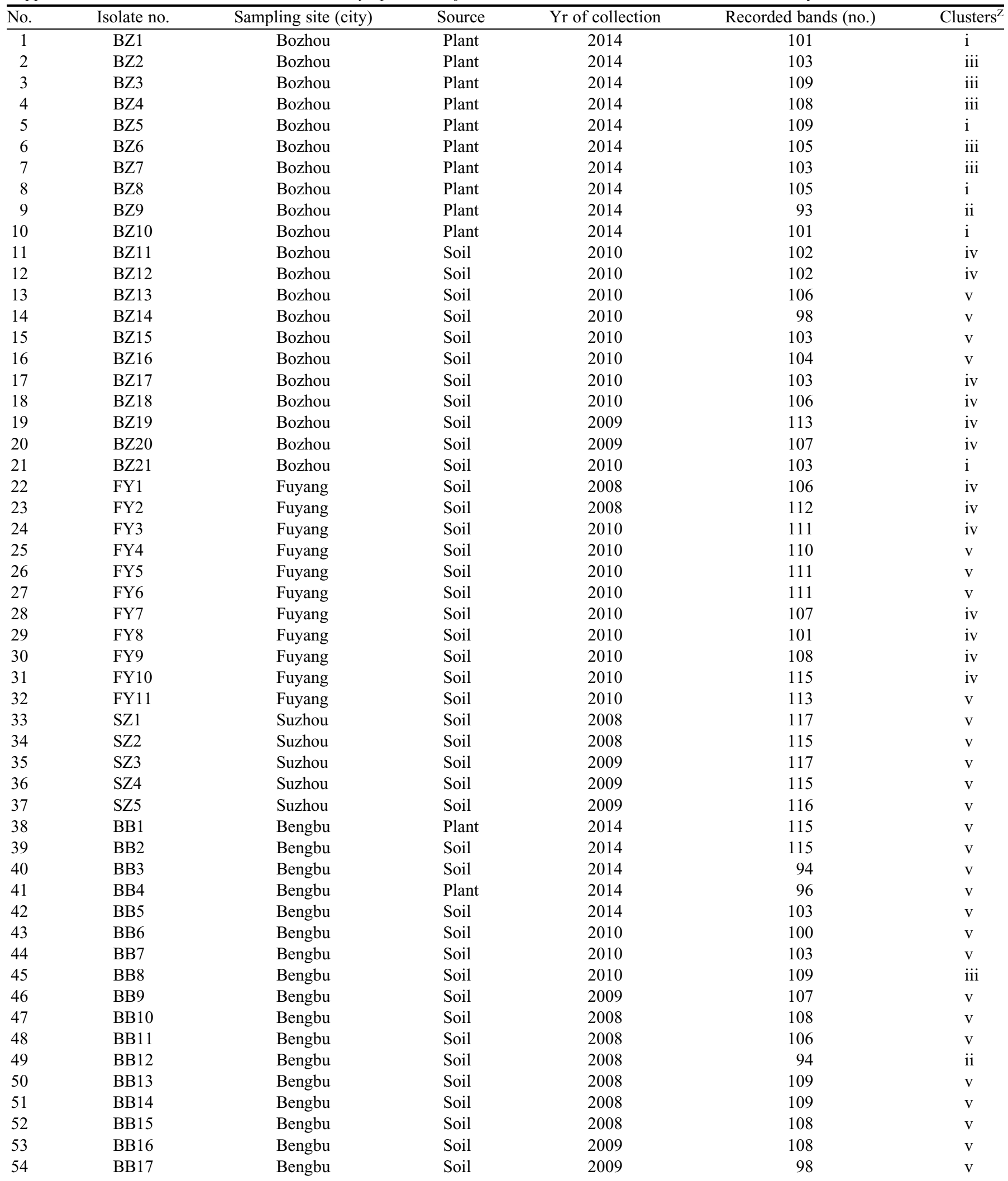

Continued next page 
Supplemental Table 1. Continued.

\begin{tabular}{|c|c|c|c|c|c|c|}
\hline No. & Isolate no. & Sampling site (city) & Source & Yr of collection & Recorded bands (no.) & Clusters $^{\mathrm{Z}}$ \\
\hline 55 & BB18 & Bengbu & Soil & 2009 & 110 & $\mathrm{v}$ \\
\hline 56 & LA1 & Luan & Soil & 2014 & 101 & $\mathrm{v}$ \\
\hline 57 & LA2 & Luan & Soil & 2014 & 97 & $\mathrm{v}$ \\
\hline 59 & LA4 & Luan & Soil & 2014 & 94 & $\mathrm{v}$ \\
\hline 60 & LA5 & Luan & Soil & 2014 & 111 & $\mathrm{v}$ \\
\hline 61 & LA6 & Luan & Soil & 2014 & 105 & $\mathrm{v}$ \\
\hline
\end{tabular}

$\overline{\mathrm{z}}$, ii, iii, iv, and $\mathrm{v}$ represent five distinct clusters based on genetic distances.

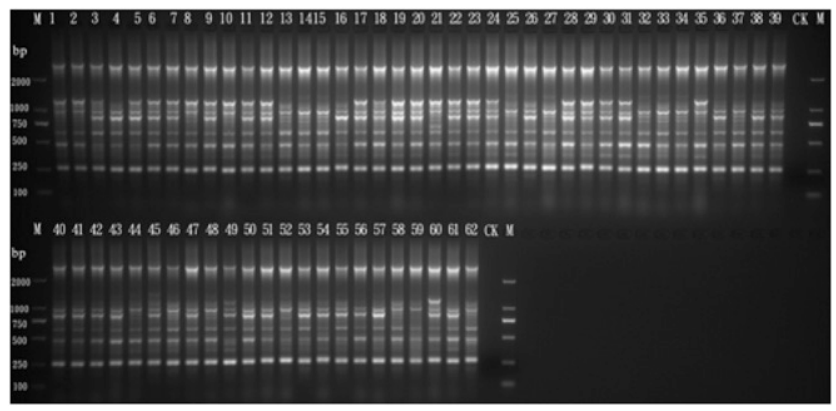

Supplemental Fig. 1. The genetic fingerprints of 62 Phytophthora sojae isolates with primer ILE7: lane M = DL 2000 marker with indicated molecular weight size (bp), lane $\mathrm{CK}=$ no DNA template, lanes 1-62 = samples listed in Supplemental Table 1. 